\title{
O OPEN ACCESS \\ Categorising sports injuries in epidemiological studies: the subsequent injury categorisation (SIC) model to address multiple, recurrent and exacerbation of injuries
}

\author{
Caroline F Finch, ${ }^{1}$ Jill Cook $^{2}$
}

${ }^{1}$ Centre for Healthy and Safe Sport (CHASS), University of Ballarat, Ballarat, Victoria, Australia

${ }^{2}$ Department of Physiotherapy, School of Primary Health Care, Monash University, Melbourne, Victoria, Australia

\section{Correspondence to} Professor Caroline Finch, Centre for Healthy and Safe Sport (CHASS), University of Ballarat, SMB Campus, PO Box 668, Ballarat, VIC 3353, Australia; c.finch@ballarat.edu.au

Accepted 13 February 2013 Published Online First 16 March 2013
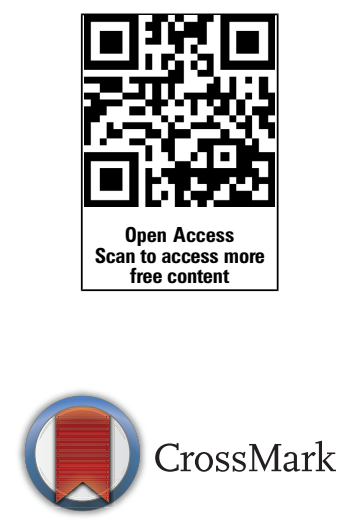

To cite: Finch CF, Cook J. Br J Sports Med 2014;48:1276-1280.

\begin{abstract}
Objective Sports injuries are often recurrent and there is wide recognition that a subsequent injury (of either the same or a different type) can be strongly influenced by a previous injury. Correctly categorising subsequent injuries (multiple, recurrent, exacerbation or new) requires substantial clinical expertise, but there is also considerable value in combining this expertise with more objective statistical criteria. This paper presents a new model, the subsequent injury categorisation (SIC) model, for categorising subsequent sports injuries that takes into account the need to include both acute and overuse injuries and ten different dependency structures between injury types.
\end{abstract}

Methods The suitability of the SIC model was demonstrated with date ordered sports injury data from a large injury database from community Australian football players over one playing season. A subsequent injury was defined to have occurred in the subset of players with two or more reported injuries.

Results 282 players sustained 469 subsequent injuries of which $15.6 \%$ were coded to categories representing injuries that were directly related to previous index injuries. This demonstrates that players can sustain a number of injuries over one playing season. Many of these will be unrelated to previous injuries but subsequent injuries that are related to previous injury occurrences are not uncommon.

Conclusion The handling of subsequent sports injuries is a substantial challenge for the sports medicine field - both in terms of injury treatment and in epidemiological research to quantify them. Application of the SIC model allows for multiple different injury types and relationships within players, as well as different index injuries.

\section{INTRODUCTION}

Sports injuries are often recurrent and there is wide recognition that a subsequent injury (of either the same or a different type) can be strongly influenced by a previous injury. ${ }^{1-5}$ Reasons for this could include similar mechanisms or risk factors (especially intrinsic risk factors) involved in injury causation or limited tissue healing from an earlier injury. ${ }^{6} 7$

The terms 'repeat', 'recurrent' or 'multiple' injuries are used in the literature interchangeably to describe instances in which more than one injury occurrence is studied. This is problematic because 'multiple/repeat' injuries could still include possibly correlated injuries that are not exactly the same (eg, an athlete sustains an ankle injury, resulting in loss of range of movement and strength and leading to other injuries such as Achilles tendinopathy or an injury further up the kinetic chain). The common use of the term 'recurrent/repeat' implies more than one occurrence of exactly the same injury, whereas 'multiple injuries' implies several different and unrelated injuries. In some applications, it would be correct to talk about either multiple or recurrent injuries alone, but there are other instances in which both type of injuries are of interest and could occur to an athlete over a specified period. For this reason, like Hamilton et $a l,{ }^{4}$ we prefer the term 'subsequent' injury to encompass both multiple and recurrent injuries, as well as to allow for 'exacerbation', which is reinjury before resolution of prior injury.

Acute injury can be defined as any physical complaint that is caused by the inability of the body's tissues to maintain its structural and/or functional integrity following an instantaneous transfer of energy to the body (eg, from an impact or sudden movement). For example, a sudden twist of the knee may cause an anterior cruciate ligament tear that causes immediate pain and functional impairment. In contrast, injuries that are caused by an accumulated energy transfer, rather than a clearly identifiable single event, are often called overuse injuries. ${ }^{89}$ However, none of the published injury definitions to date adequately cover all forms of sports injury.

Correctly categorising subsequent injuries (multiple, recurrent, exacerbation or new) is important because if correct definitions are not used, there is the potential for either under-reporting or overestimation of a new injury incidence and/or injury recurrences. ${ }^{10}$ While correct classification requires considerable clinical expertise, there is also value in combining this with more objective statistical criteria. Existing sports injury classifications are inadequate because they are unable to capture true recurrence. Moreover, there is currently no existing holistic system that has both clinical application and statistical robustness.

The aims of this paper are therefore to present a new model for categorising subsequent injuries in the sports injury context. Its application to a large injury data collection demonstrates the key features and attributes of the model. It is hoped that the model will be applied to other injury datasets and evaluated further to examine its wider application by both clinicians and researchers. 


\section{DEFINING SUBSEQUENT INJURY RISK IN RELATION TO RECOVERY FROM AN INITIAL OR INDEX INJURY}

To date, subsequent injuries have generally been considered from a clinical management and return-to-play (or time away from sport to recover from injury) perspective. ${ }^{1-3} \quad 10-12$ However, there are many issues with defining and recording subsequent injuries in the sporting context. Sports injury surveillance guidelines and several conceptual papers describe the complex issues associated with properly classifying injuries as recurrent, reinjury, exacerbations or overuse. ${ }^{4} 1314$ There has also been considerable attention given to consensus statements for sports injury surveillance, with the vast majority considering recurrent injury as one type of subsequent injury. ${ }^{13-16}$ Most of these follow the suggestions of Fuller et al, ${ }^{7}$ though a new conceptualisation of overuse injury has been proposed by Bahr, ${ }^{8}$ and a refined definition of subsequent injury was given more recently by Hamilton et al. ${ }^{4}$ Reported definitions of subsequent injury have been both sport-specific and context-specific and whether or not the person has fully or partially recovered (or continues to play injured) from a previous injury has been considered to varying degrees. 4710

The most recent taxonomy of subsequent sports injury ${ }^{4}$ recommends that injuries be coded as: (1) new injury=different location, (2) local injury=same location but different type and (3) recurrent injury=same location and same type. In this taxonomy, the last two categories represent injuries that could be correlated with an initial injury. It has been accepted that the nature (at a tissue level), rather than just the general location of the injury (eg, knee or thigh), is also important when categorising repeat injuries. ${ }^{7}$ Others have argued that a recurrent injury should only be defined as one that is of the same type occurring at the same site but only after full recovery from an earlier injury. ${ }^{713}$ None of this prior work, however, discusses subsequent injuries from a statistical viewpoint, and therefore adequate recognition of the various dependencies (or possible relationships) between injuries within players is lacking in the sports medicine literature.

\section{A NEW MODEL OF SUBSEQUENT INJURY CATEGORISATION (THE SIC MODEL)}

The SIC model is one that takes into account the need to include both acute and overuse injuries and ten different dependency structures between injury types, and is outlined in table 1. Compared to the existing sports injury definitions, it adopts a more statistically oriented approach towards categorising injury types that makes provision for all potential withinperson injury dependencies.

This approach is consistent with statistical modelling principles. ${ }^{17}$ The model was constructed using Bayesian data analysis principles that first require that a full probability model of all the possible outcomes be constructed. ${ }^{18}$ The starting point was therefore to construct a probabilistic model that included all combinations of the possible relationships between two injuries, irrespective of how likely they were. These categories were then checked to ensure that they had clinical meaning and that they were relevant to most sports injury data collections. In Bayesian statistical parlance, this is the prior predictive distribution of subsequent injury outcomes.

Table 1 also maps this new SIC model against the recent Hamilton et $a l^{4}$ subsequent injury definition and the Fuller et $a l^{7}$ recurrent/reinjury/exacerbation definitions. The overuse definitions are consistent with the approach advocated by Clarsen et al. ${ }^{19}$

It is recognised that for some real-world datasets some of the dependency categories within the SIC model may not apply (with the potential for some zero count cells), but it is still important to include them in an overall categorisation model, especially from a statistical model point of view. The categories within the SIC model are therefore holistic and intended to capture all types of subsequent injuries, while also being mutually exclusive. For example, to make a clinical case for category 5 , a back-related hamstring strain could have an unclear clinical diagnosis; at times, it could present only like a hamstring strain and at other times, only like a low back issue. A player who presents twice with this injury will fit category 5. Category 6 is

Table 1 The subsequent injury categorisation (SIC) model: classification of subsequent injuries according to the most likely clinically relevant categories with different statistical dependencies between an index injury and a subsequent injury

\begin{tabular}{|c|c|}
\hline $\begin{array}{l}\text { Subsequent injury } \\
\text { characterised by body site and } \\
\text { nature }\end{array}$ & $\begin{array}{l}\text { New classification of subsequent injury in } \\
\text { relation to an index injury i* (dependency } \\
\text { category number) }\end{array}$ \\
\hline No injury & None (1) \\
\hline $\begin{array}{l}\text { Exact same injury in terms of } \\
\text { body site and nature }\end{array}$ & $\begin{array}{l}\text { Acute onset which occurs after full recovery of index } \\
\text { injury i-related to index injury i ( } 2 \text { ) } \\
\text { Acute onset exacerbation or reinjury before full } \\
\text { recovery—related to index injury i (3) } \\
\text { Continual or sporadic experiences of pain or other } \\
\text { physical discomfort-related to index injury i (4)‡ } \\
\text { Continual or sporadic experiences of pain or other } \\
\text { physical discomfort-not related to index injury i (5)‡ } \\
\text { Not related to index injury i (6) }\end{array}$ \\
\hline $\begin{array}{l}\text { Injury to same body site but } \\
\text { different nature }\end{array}$ & $\begin{array}{l}\text { Occurrence related to index injury i (7) } \\
\text { Occurrence not related to index injury i (8) }\end{array}$ \\
\hline $\begin{array}{l}\text { Injury to different body part } \\
\text { (irrespective of nature) }\end{array}$ & $\begin{array}{l}\text { Occurrence related to index injury i (9) } \\
\text { Occurrence not related to index injury i (10) }\end{array}$ \\
\hline
\end{tabular}

Definition of Hamilton et $a l^{4}+$

Not considered

Recurrent

Reinjury

Exacerbation

Not clear

Not clear

Not considered

Local一but possibility of different relationships to index injury not considered

New-but possibility of different relationships to index injury not considered

* It is possible for there to be more than one index in a given sequence of injuries and the term index injury i refers to the ith index injury. $i=1,2$, etc

tThese categorisations do not explicitly recognise new (multiple) index injuries, but the concept can be easily incorporated.

‡Categories relating to overuse injuries with no acute onset of symptoms. 
easier to define and would include cases such as a player who sustains a fracture from a direct blow in one season and then fully recovers but sustains a similar fracture in the following season; this clearly fits category 6 rather than categories 7-10. Similarly, the category 'no injury' is included for model completeness from a statistical viewpoint, but is expected to have zero counts.

\section{USING THE SIC MODEL TO CATEGORISE INJURIES: INCORPORATING MULTIPLE INDEX INJURIES}

Consistent with the Bayesian statistical modelling approach, ${ }^{18}$ the next stage was to calculate the posterior probability distribution by applying the model to an existing dataset and, in this case, to count the number of injury cases assigned to each category.

Comparison in a pairwise fashion to an earlier injury is required to assess the recurrent nature of an injury. Access to reliable information before the first injury recorded or onset of the problem is difficult, and so the first index injury needs to be taken as the first recorded injury for a given athlete in a case series or new study. Using data from existing prior sources could potentially bias the data in relation to the duration and quality of the information contained in those records. For overuse injuries, this first index injury can only be taken to be the first (recorded) time presentation of symptoms as there is no way to determine loss of structural and functional integrity of body tissue that remains asymptomatic, and asymptomatic pathology in the sporting population is high.

Depending on the nature of the first index injury, it may not be reasonable to assume that all subsequent injuries will be related to that one. If an athlete sustains several injuries, and these are recorded in sequence, then it is possible that there will be different index injuries. This is analogous to the competing risks issue that arises in survival analysis where people can be at risk of several different health problems at the same time. ${ }^{20}$ To allow for competing injury risks, the model needs to allow different and multiple index injuries.

\section{APPLICATION OF THE SIC MODEL TO SPORTS INJURY DATA}

The suitability of the SIC model was assessed with sports injury data from the Preventing Australian Football Injuries through eXercise (PAFIX) study. Full details of the study methods and data collection processes have been published elsewhere, ${ }^{21} 22$ as has a specific description of the nature, body region and cause of these injuries. ${ }^{23}$ All injuries were assigned a diagnosis code according to the internationally recognised Orchard Sports Injury Coding System (OSICS-10). ${ }^{24}$

The OSICS-10 codes assigned to each injury were used to categorise them, and decisions were supplemented with the body region and nature of injury codes, as well as text narrative descriptions of the injury events. All injuries for a given person were ordered by date of occurrence, to provide a temporal sequence of injuries for each player. The first injury was taken to be the first index injury against which the SIC model was applied, but it was also recognised that there could be more than one index injury within a given series of injuries in some athletes.

Over the 2007 and 2008 playing seasons, the PAFIX study prospectively recorded 1082 injuries sustained by 1564 community Australian football players. ${ }^{21}$ A total of $36 \%$ of the players sustained at least one injury (range 1-8).

All injuries were ordered sequentially according to the date of their occurrence to determine the first index injury and all other subsequent injuries following it (either another index injury or related injuries). A subsequent injury was defined to have occurred in the subset of players with two or more reported injuries. Overall, 469 subsequent injuries were sustained by 282 players. According to the Hamilton et $a l^{4}$ sports injury taxonomy, $12 \%$ of these subsequent injuries were recurrent and hence likely to be dependent on previous injuries (table 2).

Table 3 classifies the 469 subsequent injuries in the PAFIX dataset according to the SIC model categories, relative to the first injury recorded in the dataset (ie, the first index injury) and other identified subsequent index injuries. This table shows what the model looks like when applied to a sports injury dataset and provides the Bayesian posterior distribution ${ }^{18}$ of the model categories. The most likely reason for there being no cases coded to category 6 and this dataset recorded injuries to players over one playing season only. Collectively, $15.6 \%$ of all subsequent injuries in the PAFIX community Australian football injury dataset would be coded to categories representing injuries that are directly related to previous index injuries. This can be contrasted to the $12 \%$ shown in table 2 , where injuries were categorised according to the Hamilton et al ${ }^{4}$ scheme.

\section{Multiple index injuries}

One of the challenges with coding injury data from sequences of this type collected over a period of time (eg, a playing season) is identifying index injuries as the 'subsequent' injury status always needs to be determined in relation to an earlier injury in a series. When players only sustain two injuries, the first chronological injury is taken as the index injury and the

Table 2 Type of subsequent injury sustained by community football players, according to the classification by Hamilton et al ${ }^{4}$

\begin{tabular}{|c|c|c|c|c|c|}
\hline \multirow{2}{*}{$\begin{array}{l}\text { Number of injuries } \\
\text { per player }\end{array}$} & \multirow[b]{2}{*}{ Number of players } & \multirow{2}{*}{$\begin{array}{l}\text { Total number of } \\
\text { subsequent injuries }\end{array}$} & \multicolumn{3}{|c|}{$\begin{array}{l}\text { Number (\%) of subsequent injuries according to injury } \\
\text { category }\end{array}$} \\
\hline & & & New & Local & Recurrent \\
\hline 2 & 161 & 161 & $128(80 \%)$ & $18(11 \%)$ & $15(9 \%)$ \\
\hline 3 & 86 & 172 & $133(77 \%)$ & $18(11 \%)$ & $21(12 \%)$ \\
\hline 4 & 18 & 54 & $36(67 \%)$ & $12(22 \%)$ & $6(11 \%)$ \\
\hline 5 & 8 & 32 & $23(71 \%)$ & $4(13 \%)$ & $5(16 \%)$ \\
\hline 6 & 5 & 25 & $20(80 \%)$ & $2(8 \%)$ & $3(12 \%)$ \\
\hline 7 & 3 & 18 & $10(55 \%)$ & $2(11 \%)$ & $6(34 \%)$ \\
\hline 8 & 1 & 7 & $5(71 \%)$ & $2(29 \%)$ & 0 \\
\hline Total & 282 & 469 & $355(76 \%)$ & $58(12 \%)$ & $56(12 \%)$ \\
\hline
\end{tabular}


Table 3 Application of the subsequent injury categorisation model to the categorisation of injuries and their likely dependency, subsequent to an index injury in community Australian football players ( $n=282$ players, 469 injuries)

\begin{tabular}{|c|c|c|}
\hline $\begin{array}{l}\text { Subsequent injury characterised by } \\
\text { body site and nature }\end{array}$ & $\begin{array}{l}\text { New classification of subsequent injury in relation to index } \\
\text { injury* (dependency category number) }\end{array}$ & $\begin{array}{l}\text { Percentage of all injuries in PAFIX players } \\
\text { with } \geq 2 \text { injuries }(n=456) \text { coded to this category, } \\
\text { allowing for different index injuries }\end{array}$ \\
\hline No injury & None (1) & 0 \\
\hline \multirow[t]{5}{*}{$\begin{array}{l}\text { Exact same injury in terms of body site } \\
\text { and nature }\end{array}$} & $\begin{array}{l}\text { Acute onset which occurs after full recovery of index injury- } \\
\text { related to index injury (2) }\end{array}$ & 3.6 \\
\hline & $\begin{array}{l}\text { Acute onset exacerbation or reinjury before full recovery-related } \\
\text { to index injury (3) }\end{array}$ & 8.9 \\
\hline & $\begin{array}{l}\text { Continual or sporadic experiences of pain or other physical } \\
\text { discomfort-related to index injury (4) } \dagger\end{array}$ & 0.6 \\
\hline & $\begin{array}{l}\text { Continual or sporadic experiences of pain or other physical } \\
\text { discomfort-not related to index injury (5) }\end{array}$ & 0.4 \\
\hline & Not related to index injury (6) & 0 \\
\hline \multirow{2}{*}{$\begin{array}{l}\text { Injury to same body site but different } \\
\text { nature }\end{array}$} & Occurrence related to index injury (7) & 0.2 \\
\hline & Occurrence not related to index injury (8) & 7.4 \\
\hline \multirow{2}{*}{$\begin{array}{l}\text { Injury to different body part (irrespective } \\
\text { of nature) }\end{array}$} & Occurrence related to index injury (9) & 2.6 \\
\hline & Occurrence not related to index injury (10) & 76.3 \\
\hline
\end{tabular}

Shaded cells indicate instances where there is some statistical dependency (eg, relatedness) among injury types.

*This table includes categorisations against all index injuries (not just the first injury), when they could be identified.

subsequent status of the second injury is determined in relation to that index injury. However, when players sustain more than two injuries, it is possible that the first injury is no longer the appropriate index injury for subsequent injuries. For example, one player sustained the following four injuries sequentially by date order: fracture of finger (OSICS-10: WFFX), fracture of finger (OSICS-10: WFFX), lower leg muscle injury (OSICS-10: QMXX), lower leg muscle injury (OSICS-10: QMXX). It was considered that the second injury was subsequent and related to the first one but that the third injury, while subsequent to the first two, was not related to either of them. The fourth injury was unrelated to the first two but related to the third injury, and so the third injury was taken to be a second index injury for the purposes of assigned clarification codes.

Table 4 summarises the number of different index injuries found in the PAFIX data, according to the cases with specific overall numbers of injury. For example, of those players with three injuries, 50 (58.1\%) had three unique/index injuries, 34 (39.5\%) had two index injuries and $2(2.3 \%)$ had one index injury. Similarly, of the players with two injuries, just over one in seven players $(15.5 \%)$ had only one index injury, with the second injury being related to the first one.

Table 4 Distribution of the number of unique index injuries in the sets of injuries sustained by community football players over one playing season

\begin{tabular}{lcrrrrrr}
\hline & & \multicolumn{7}{l}{$\begin{array}{l}\text { Number of players with } \\
\text { this number of index } \\
\text { injuries }\end{array}$} \\
\cline { 2 - 7 } $\begin{array}{l}\text { Overall number } \\
\text { of injuries }\end{array}$ & $\begin{array}{l}\text { Number of players with } \\
\text { this number of injuries }\end{array}$ & $\mathbf{1}$ & $\mathbf{2}$ & $\mathbf{3}$ & $\mathbf{4}$ & $\mathbf{5}$ & $\mathbf{6}$ \\
\hline 8 & 1 & 0 & 0 & 0 & 0 & 0 & 1 \\
7 & 3 & 0 & 0 & 1 & 0 & 2 & 0 \\
6 & 5 & 0 & 0 & 2 & 0 & 1 & 2 \\
5 & 8 & 0 & 2 & 0 & 3 & 3 & \\
4 & 18 & 0 & 4 & 9 & 5 & & \\
3 & 86 & 2 & 34 & 50 & & & \\
2 & 161 & 25 & 136 & & & & \\
\hline
\end{tabular}

\section{DISCUSSION}

Preventing subsequent injury and optimising its clinical management require a strong evidence base. Although understanding the reasons for subsequent injury needs to be based on clinical principles, robust and correctly analysed high quality data from prospective sports injury research studies that are appropriately classified can better guide prevention and clinical management, especially at the population level. ${ }^{15}$ This means that there is a strong need for a set of objective and validated subsequent injury definitions that can (1) be appropriately applied to different settings where various within-player injury dependencies occur and (2) provide a logical inclusion of both acute and overuse injuries in one sports injury model.

Our application of the SIC model to an existing injury data collection shows that players can sustain a number of injuries over one playing season, and although most of these are unrelated, subsequent injuries that are related to previous injury occurrences are not uncommon. This has implications for injury prevention because a mixture of strategies will need to be implemented to prevent the initial occurrence of both new index injuries and those that are related to previous injuries. Prevention of the related subsequent injuries may require improved injury recovery and rehabilitation processes and there is a clear role for sports medicine professionals in this.

Preventing sports injury requires players' ability to tolerate repeated exposures to injury risks while being active in their sport. Better identification of risk factors leading to an initial (index) injury may help identify strategies for preventing similar subsequent injuries, especially when intrinsic risk factors play a major role. It is also possible that risk factors for a subsequent injury could be implicated in the initial injury, but they were not addressed before the subsequent injury. Of course, this is dependent on a better understanding of which types of injury occurrences are related and why this is so.

Subsequent injuries could also occur because injured players continue to participate in their sport with some modification of their techniques, physical adaptation or maladaptation, complete/incomplete recovery from injury or a combination thereof. This means that their risk of further injury will no longer be the same as for their first injury, and this change in risk is not 
considered in many studies. The fact that there are so many index injuries casts further doubt on studies which only report the first injury or time to first injury, as these are clearly ignoring valuable data on many injury cases. Coding of data according to the SIC model shows that more injuries (15.6\%) were directly related to previous index injuries than would be identified by using the Hamilton et $a l^{4}$ injury classification schemes. Identifying all related injuries is also critical to better management of injuries.

Any modelling of subsequent injury is dependent on the data collected in sports injury studies and two key issues require attention. Robust data collection techniques require attention if this model is to work adequately. Ensuring that there are clear definitions of recurrence, aggravation and exacerbation, as are provided by the SIC model, would help in identifying if the injuries were new index injuries. This paper used a Bayesian statistical modelling approach ${ }^{18}$ to underpin the SIC model, and its ability to accurately model sports injury data depends on both of these factors. As with any Bayesian statistical model, it will be important that the SIC model is further tested with other prospectively collected sports injury data by other researchers.

Most of the subsequently published sports injury studies have been restricted to one playing season because players are not exposed to injury risk when they are not participating in their sport. This is an issue in aetiological studies because a higher risk of subsequent injury could manifest in the next playing season, and therefore restricting studies to only one playing season probably underestimates the risk of subsequent injury. ${ }^{4}$ The few studies that have followed players over consecutive seasons have then treated each season as an independent observation period, and accumulated injury counts over all seasons. Moreover, injuries that do not occur during a playing season are often ignored, even though it could well be expected that injured players would have their treatment and conditioning regimens maintained or even increased in the off-season. ${ }^{10}$ Injuries that occur in the 'off-season' or 'pre-season' are not reported in incidence studies that only report new injury occurrences during a playing season, even if they could influence subsequent injury during that season. There is a clear need for sports injury studies to incorporate injury experiences over more than one season, as well as during the off-season periods, if they are to describe the incidence of subsequent injury accurately over time.

A better understanding of the nature, causes and outcomes of subsequent injuries will have major implications for sports medicine clinical practice because returning players to preinjury function, ensuring recovery of their physical functioning and preventing future injuries are the major goals of treatment. From the preventive health, clinical treatment and injury management perspectives, subsequent injuries are problematic for players, as well as for the coaches who need to manage their training and participation workloads and the clinicians who manage the rehabilitation and recovery from those injuries. ${ }^{25}$ Importantly, just because an injured player has no symptoms does not mean that they have had full tissue recovery. 8926

In conclusion, the recognition and handling of subsequent sports injuries pose a substantial challenge for the sports medicine field-both in terms of injury treatment and in epidemiological research to quantify them. This study has found that about one in six (or 15.6\%) of all subsequent sports injuries should be coded to categories representing injuries that are directly related to previous index injuries. Moreover, injured sports participants can sustain both recurrent injuries and the same injury again, and either can be dependent upon earlier index injuries. Importantly, this study has also shown that it is likely to be inappropriate to use the same index (eg, only the first injury in a chronological sequence) for all subsequent injuries. Together, this justifies the applicability of the SIC model through its ability to allow for multiple different injury types within players that recognises that the within-player dependencies are likely to be stronger for recurrent (exact same) injuries or injury exacerbations, rather than multiple (different but new) injury outcomes.

In summary, this paper sets out a holistic way of reviewing subsequent injuries that has strong clinical application and relevance. The SIC model needs further evaluation through application to other datasets, but the only way to do that is to put it out for evaluation by other epidemiologists. There will still be challenges in knowing how to best analyse the data classified according to the SIC model, but the frailty survival model approach recently advocated by Ullah and colleagues ${ }^{5} 27$ and multistate process survival models show promise.

\section{What are the new findings?}

- This paper presents a new model to categorise subsequent (multiple, recurrent, exacerbation or new) sports injuries, derived from statistical considerations of dependencies between different injuries and sports medicine clinical considerations.

- Greater capacity to classify subsequent injuries will allow improved understanding of the effect of initial injury on reinjury and injury exacerbations for both clinical management and injury prevention.

Acknowledgements Kathy Diamantopoulou (ACRISP, MIRI) undertook the data extraction and some data coding. Tom Ranger (Department of Physiotherapy) also assisted with the injury coding. The categorised data were extracted from the PAFIX database, which was generated through a separate NHMRC project grant (ID 400937, chief investigators CF Finch, DG Lloyd and BC Elliott; project coordinators D Twomey and T Doyle). Rory Wolfe and John Orchard are thanked for their comments on a draft version of this model. This work was conducted as part of the research programme of the Australian Centre for Research into Injury in Sports and its Prevention (ACRISP), one of the International Research Centres for Prevention of Injury and Protection of Athlete Health supported by the International Olympic Committee (IOC).

Contributors CFF conceived the study, led the development of the new model and had major responsibility for the writing of the paper. JC contributed to the development of the model, coordinated the injury diagnosis classification and contributed to the writing of the paper.

Funding CFF was supported by an NHMRC Principal Research Fellowship (ID 565900). The Australian (entre for Research into Injury in Sport and its Prevention (ACRISP) is one of the International Research Centres for Prevention of Injury and Protection of Athlete Health supported by the International Olympic Committee (IOC).

Competing interests None.

Provenance and peer review Not commissioned; externally peer reviewed.

Open Access This is an Open Access article distributed in accordance with the Creative Commons Attribution Non Commercial (CC BY-NC 3.0) license, which permits others to distribute, remix, adapt, build upon this work non-commercially, and license their derivative works on different terms, provided the original work is properly cited and the use is non-commercial. See: http://creativecommons.org/ licenses/by-nc/3.0/

\section{REFERENCES}

1 Hagglund $\mathrm{M}$, Walden $\mathrm{M}$, Ekstrand J. Previous injury as a risk factor for injury in elite football: a prospective study over two consecutive seasons. Br J Sports Med 2006;40:767-72. 
2 de Visser $\mathrm{H}$, Reijman $\mathrm{M}$, Heijboer $\mathrm{M}$, et al. Risk factors of recurrent hamstring injuries: a systematic review. Br J Sports Med 2012;46:124-30.

3 Swenson D, Yard E, Fields $S$, et al. Patterns of recurrent injuries among US high school athletes, 2005-2008. Am J Sports Med 2009;37:1586-93.

4 Hamilton G, Meeuwisse W, Emery C, et al. Subsequent injury definition, classification and consequence. Clin J Sport Med 2011;21:508-14.

5 Ullah S, Gabbett T, Finch C. Statistical modelling for recurrent events: an application to sports injuries. Br J Sports Med 2014;48:1287-93.

6 Meeuwisse W, Tyreman H, Hagel B, et al. A dynamic model of etiology in sport injury: the recursive nature of risk and causation. Clin J Sport Med 2007;17:215-19.

7 Fuller CW, Bahr R, Dick RW, et al. A framework for recording recurrences, reinjuries, and exacerbations in injury surveillance. Clin J Sport Med 2007:17:197-200.

8 Bahr R. No injuries, but plenty of pain? On the methodology for recording overuse symptoms in sports. Br J Sports Med 2009:43:966-72.

9 Cook J, Finch C. The long-term impact of overuse injuries on life-long participation in sport and health status. In: Farelli A Sport participation: health benefits, injuries, and psychological effects, chapter 3. New York: Nova Science Publishers Ltd., 2011: 85-104.

10 Hammond L, Lilley J, Pope $\mathrm{G}$, et al. Considerations for the interpretation of epidemiological studies of injuries in team sports: illustrative examples. Clin J Sport Med 2011:21:77-9.

11 Croisier J-L. Factors associated with recurrent hamstring injuries. Sports Med 2004;34:681-95.

12 Hollis $\mathrm{S}$, Stevenson M, McIntosh A, et al. Mild traumatic brain injury among a cohort of rugby players: predictors for time to injury. Br J Sports Med 2011:45:997-9.

13 Fuller $C$, Ekstrand J, Junge $A$, et al. Consensus statement on injury definitions and data collection procedures in studies of football (soccer) injuries. Br J Sports Med 2006:40:193-201.

14 Fuller C, Molloy M, Bagate $\mathrm{C}$, et al. Consensus statement on injury definitions and data collection procedures for studies of injuries in rugby union. Br J Sports Med 2007;41:328-31.
15 Finch C. An overview of some definitional issues for sports injury surveillance. Sports Med 1997;24:157-63.

16 Orchard J, Newman D, Stretch $\mathrm{R}$, et al. Methods for injury surveillance in international cricket. J Sci Med Sport 2005;8:1-14.

17 Dobson A. An introduction to statistical modelling. London: Chapman and Hall Ltd, 1983.

18 Gelman A, Carlin J, Stern H, et al. Bayesian data analysis. 2nd edn. Boca Raton, FL: Chapman \& Hall/CRC, 2004.

19 Clarsen B, Myklebust G, Bahr R. Development and validation of a new method for the registration of overuse injuries in sports injury epidemiology. 2012.

20 Crowder M. Multivariate survival analysis and competing risks. Boca Raton, FL: Taylor \& Francis Group, 2012

21 Finch C, Lloyd D, Elliott B. The Preventing Australian Football Injuries with eXercise (PAFIX) study: a group randomised controlled trial. Inj Prev 2009;15:e1 .

22 Twomey D, Finch C, Doyle T, et al. Level of agreement between field-based data collectors in a large scale injury prevention randomised controlled trial. I Sci Med Sport 2011;14:121-5

23 Finch $C$, Gabbe $B$, White $P$, et al. Priorities for investment in injury prevention in community Australian football. Clin J Sport Med 2013 (in press)

24 Finch C, Orchard J, Twomey D, et al. Coding sports injury diagnoses in epidemiological studies - does the background of the coder matter? Br J Sports Med 2014;48:552-6.

25 Crossley K, Thancanamootoo K, Metcalf BR, et al. Clinical features of patellar tendinopathy and their implications for rehabilitation. J Ortho Res 2007;25: 1164-75.

26 Gravare Silbernagel K, Thomee R, Eriksson B, et al. Full symptomatic recovery does not ensure full recovery of muscle-tendon function in patients with Achilles tendinopathy. Br J Sports Med 2007;41:276-80.

27 Gabbett TJ, Ullah S, Finch CF. Identifying risk factors for contact injury in professional rugby league players - application of a frailty model for recurrent injury. J Sci Med Sport 2012;15:496-504. 